Research paper

\title{
Exploring the enzymatic degradation of poly(glycerol adipate)
}

\author{
Sadie M.E. Swainson ${ }^{\mathrm{a}}$, Vincenzo Taresco ${ }^{\mathrm{a}}$, Amanda K. Pearce ${ }^{\mathrm{a}}$, Lucie H. Clapp ${ }^{\mathrm{b}}$, Barry Ager ${ }^{\mathrm{c}}$, \\ Mark McAllister ${ }^{\mathrm{c}}$, Cynthia Bosquillon ${ }^{\mathrm{a}}$, Martin C. Garnett ${ }^{\mathrm{a}, *}$ \\ ${ }^{a}$ School of Pharmacy, University of Nottingham, Nottingham NG7 2RD, United Kingdom \\ ${ }^{\mathrm{b}}$ Department of Medicine, University College London, London WC1E 6JF, United Kingdom \\ ${ }^{\mathrm{c}}$ Drug Product Design, Pfizer Ltd, Sandwich CT13 9ND, United Kingdom
}

\section{A R T I C L E I N F O}

\section{Keywords:}

Poly(glycerol adipate)

Enzymatic degradation

Polyester

Biodegradable

Polymer modification

Breakdown

\begin{abstract}
A B S T R A C T
Poly(glycerol adipate) (PGA) is a biodegradable, biocompatible, polymer with a great deal of potential in the field of drug delivery. Active drug molecules can be conjugated to the polymer backbone or encapsulated in selfassembled nanoparticles for targeted and systemic delivery. Here, a range of techniques have been used to characterise the enzymatic degradation of PGA extensively for the first time and to provide an indication of the way the polymer will behave and release drug payloads in vivo. Dynamic Light Scattering was used to monitor change in nanoparticle size, indicative of degradation. The release of a fluorescent dye, coupled to PGA, upon incubation with enzymes was measured over a $96 \mathrm{~h}$ period as a model of drug release from polymer drug conjugates. The changes to the chemical structure and molecular weight of PGA following enzyme exposure were characterised using FTIR, NMR and GPC. These techniques provided evidence of the biodegradability of PGA, its susceptibility to degradation by a range of enzymes commonly found in the human body and the polymer's potential as a drug delivery platform.
\end{abstract}

\section{Introduction}

Poly(glycerol adipate) (PGA) is synthesised by enzymatic polymerisation from glycerol and either divinyl adipate, dimethyl adipate or adipic acid, using Novozym 435 lipase as the catalyst, allowing a high degree of control over the final product [1-4]. Enzymatic polymerisation is an emerging area of research which provides several benefits as a method for producing materials for drug delivery compared with more traditional synthesis methods. The avoidance of metal catalysts removes the risk of toxic metals in the final product, while the use of an enzyme catalyst enables high levels of enantio-, chemo- and regioselectivity using mild reaction conditions [1]. PGA self-assembles to form nanoparticles [5] which, with varying levels of stearic acid modification, have been shown to have low cytotoxicity in HL-60 and $\mathrm{HepG}_{2}$ cells $[6,7]$. Unmodified PGA and PGA with a range of amino acid modifications have also been shown to have negligible lytic activity in a haemolytic assay [8]. The presence of the pendant $-\mathrm{OH}$ group in the polymer backbone allows for the conjugation of molecules with a variety of functional groups through simple coupling reactions, influencing the physicochemical properties of PGA and its ability to encapsulate a variety of drugs $[6,8-10]$. These changes to the polymer as a result of the modifications suggest the enzymatic degradation will be affected due to the enhanced stability, altered hydrophobicity and increased steric hindrance, leading to a potential for tunable breakdown and release in vivo. Previously, this has been demonstrated through functionalisation of PGA with N-acyl amino acids via Steglich Esterification [8]. Additionally, the drug molecules indomethacin [11], methotrexate [12] and ibuprofen [13] have been successfully coupled to the polymer backbone. The low toxicity of PGA coupled with the ease with which it can be synthesised, functionalised with drug molecules and formulated into nanoparticles means it shows great potential as a polymeric platform for both targeted and systemic drug delivery.

It is important to understand the degradation properties of polymers for a number of reasons. From a safety point of view, an awareness of likely breakdown products facilitates the prediction of potential in vivo toxicity. Taking PGA as an example, the breakdown products would be expected to be the starting materials, glycerol and adipic acid, as the ester bond represents a fairly weak and susceptible point of cleavage $[1,6,14-17]$; however without investigation into these breakdown products it is not possible to guarantee the biocompatibility of this polymer. Furthermore, knowledge of the cleavage of the pendant side chains, and the resultant breakdown products, will enable prediction of the likely in vivo safety profile, prior to cytotoxicity testing of the breakdown products themselves. Secondly, polymers can be formulated

\footnotetext{
* Corresponding author.

E-mail address: martin.garnett@nottingham.ac.uk (M.C. Garnett).
} 
into nano- and microparticles; the breakdown of these particles will affect the mechanisms by which they are cleared from the body [18] and the release of drug payloads. In terms of efficacy, any drug coupled to or encapsulated within a polymer tends to require release in order to achieve therapeutic efficacy $[14,15,19]$. Consequently, understanding the way in which this release takes place will inform the design of dosage regimens and subsequent pharmacokinetic experiments. Additionally, susceptibility or indeed a resistance to particular enzymes may impact on the suitability of a specific polymer for different routes of administration and disease targets [15]. Understanding the enzymatic breakdown of PGA and consequently the way it will behave in vivo will help to inform any future dosage form design and provide an indication of the safety and efficacy of formulations prior to costly in vitro and in vivo experiments.

Previously, the release of methotrexate from a PGA-drug conjugate has been studied in the presence of porcine carboxylesterase. The enzyme was seen to increase the release of methotrexate compared with buffer alone over a period of seven days [12]. This work suggested the polymer was susceptible to enzymatic degradation but did not focus on the nature of this degradation in detail or examine the degradation products. Additionally, the degradation of poly(glycerol sebacate) (PGS), a polymer with structural similarity to PGA, has been studied by several groups. However, it is worth noting that PGS is a cross-linked polymer, whereas the PGA in the present study is not cross-linked and largely linear [20-22]. PGS is an elastomer which may be of utility as a tissue scaffold and consequently degradation experiments have tended to focus on bulk characteristics such as the change in film weight and thickness over a period of hours or days. In the case of tissue scaffolds, degradation if too rapid, tends to be seen as a disadvantage. However, as previously mentioned, for drug delivery breakdown of the polymer at the target site is greatly advantageous.

The enzymatic degradation, in the presence of six enzymes, of PGA and a selection of amino acid modified polymers has been studied in detail here for the first time alongside two new modifications of PGA; PGA-Carboxyfluorescein, at two levels of substitution, and PGA-poly (ethylene glycol) (PGA-PEG). Pancreatin, pepsin, lipase and trypsin were selected as examples of gastrointestinal enzymes in order to give an indication of the general degradation behaviour of the polymer and to assess the potential future suitability of PGA for encapsulation or coating of oral dosage forms. Esterase was selected as it can be detected in many areas of the body whereas elastase is associated with acute and chronic inflammation in many diseases [23]. A range of techniques has been employed to allow a comprehensive evaluation of the enzymatic degradation behaviour of PGA and relative susceptibility to different enzymes. Dynamic Light Scattering (DLS) was used as a rapid screening method to provide information about particle breakdown and to facilitate the selection of enzyme concentrations and conditions. A fluorescent dye, carboxyfluorescein, coupled to the polymer, was used as a model of polymer drug conjugates, and as a model for other pendant groups esterified to the free hydroxyl group, in order to study release over time. Finally, Nuclear Magnetic Resonance (NMR), FourierTransform Infra-Red (FTIR) and Gel Permeation Chromatography (GPC) were combined to characterise the breakdown of the polymer and identify the breakdown products.

\section{Materials \& methods}

\subsection{Materials}

Tetrahydrofuran (THF, HPLC grade), petroleum ether (reagent grade), acetone (HPLC grade), dimethylformamide (DMF, HPLC grade), sodium hydroxide $(\mathrm{NaOH}, 2 \mathrm{M})$, HEPES and boric acid were purchased from Fisher Scientific (Loughborough, UK). Sodium Benzoate $(0.1 \%)$ was purchased from Alfa Aesar (Heysham, UK). Divinyl adipate was purchased from Tokyo Chemical Industry (Oxford, UK). Acetone- $d_{6}$ was purchased from Acros Organics (Geel, Belgium). Novozym 435 (immobilised on acrylic resin), glycerol, 5(6)-carboxyfluorescein (CF), poly(ethylene glycol) (PEG) methyl ether, 4-dimethylaminopyrridine (DMAP), N,N'-dicyclohexylcarbodiimide (DCC), phosphate buffered saline (PBS) tablets, Trizma base, potassium phosphate monobasic, hydrochloric acid ( $\mathrm{HCl}, 5 \mathrm{M})$, sodium chloride, N-succinyl-L-Ala-AlaAla-p-nitroanilide, ethyl butyrate, 4-methylumbellifyl butyrate, 4-methyl umbelliferone, Na-benzoyl-L-arginine ethyl ester, deuterium oxide and sodium phosphate monobasic were purchased from Sigma-Aldrich (Poole, UK). Elastase from porcine pancreas Type I ( $\geq 4.0$ units $/ \mathrm{mg}$ protein), esterase from porcine liver ( $\geq 15$ units/mg solid), lipase from porcine pancreas (Type II, $100-500$ units/mg protein (using olive oil (30 min incubation)), 30-90 units/mg protein (using triacetin)), pancreatin from porcine pancreas (8x USP), pepsin from porcine gastric mucosa ( $\geq 250$ units $/ \mathrm{mg}$ solid) and trypsin from porcine pancreas (lyophilized powder, 1000-2000 BAEE units/mg solid) were also purchased from Sigma-Aldrich (Poole, UK).

\subsection{PGA synthesis}

PGA was synthesised following the protocol detailed by Taresco et al. [1]. Briefly, glycerol (125 mmol) and divinyl adipate $(125 \mathrm{mmol})$ were placed in a three-necked round bottom flask with anhydrous tetrahydrofuran (THF, $50 \mathrm{ml})$. Novozym $435(1.1 \mathrm{~g})$ was added and the resultant mixture stirred at $250 \mathrm{rpm}$ with an overhead stirrer for $24 \mathrm{~h}$ at $50{ }^{\circ} \mathrm{C}$. After this time the immobilised enzyme was removed by filtration and the THF by rotary evaporation. The residue was heated at 90-95 ${ }^{\circ} \mathrm{C}$ for $1 \mathrm{~h}$ to deactivate any residual enzyme.

\subsection{PGA modifications}

PGA-Carboxyfluorescein at two target substitution levels (1\% mol/ $\mathrm{mol} \& 5 \% \mathrm{~mol} / \mathrm{mol}, \mathrm{PGA}-\mathrm{CF}$ and PGA-CF5, respectively) and PGA-PEG ( $2 \% \mathrm{~mol} / \mathrm{mol}$ substitution) were synthesised using a Steglich Esterification, as previously detailed by Taresco et al. [8] This procedure was also used to synthesise PGA-Phe10, PGA-Phe50, PGA-Trp10 and PGA-Trp50; these modifications affect the physicochemical properties of the polymer. Phe refers to phenylalanine, Trp to tryptophan and the number reflects the molar percentage of substitution. The complete reaction scheme for both the production and modification of PGA is shown in Fig. 1. ${ }^{1} \mathrm{H}$ NMR was used to characterise PGA-CF, PGACF5 and PGA-PEG and confirm the couplings were successful; this can be found in Appendix A1-A3 respectively, whereas the characterisation of the amino acid modified polymers has previously been discussed by Taresco et al. [8].

\subsection{Nanoparticle preparation}

Nanoparticles were prepared by nanoprecipitation to a final concentration of $1 \mathrm{mg} / \mathrm{ml}$. Polymers were dissolved in acetone $(1 \mathrm{ml})$ and added dropwise to ultrapure water under magnetic stirring. The solvent was then allowed to evaporate fully. All nanoparticles had a hydrodynamic diameter between 50 and $150 \mathrm{~nm}$, measured by DLS (Zetasizer Nano ZS, Malvern Instruments, Malvern, Worcester).

\subsection{Dynamic light scattering}

Enzyme solutions ( $50 \mu \mathrm{l})$ were added to nanoparticle suspensions $(250 \mu \mathrm{l})$ and the change in size over time at $25^{\circ} \mathrm{C}$ was measured by DLS. The hydrodynamic diameter of the particles, henceforth referred to as the particle size, was measured at a scattering angle of $173^{\circ}$. Buffer controls, with no enzyme, were also studied to differentiate the effect of the enzyme from that of the buffer. The concentration of the enzyme solution was chosen based on examples from literature, where possible. Where this information was not available several concentrations were trialled to find the optimum level. The assay was stopped when the polydispersity exceeded 0.8 , insufficient sample remained for accurate 

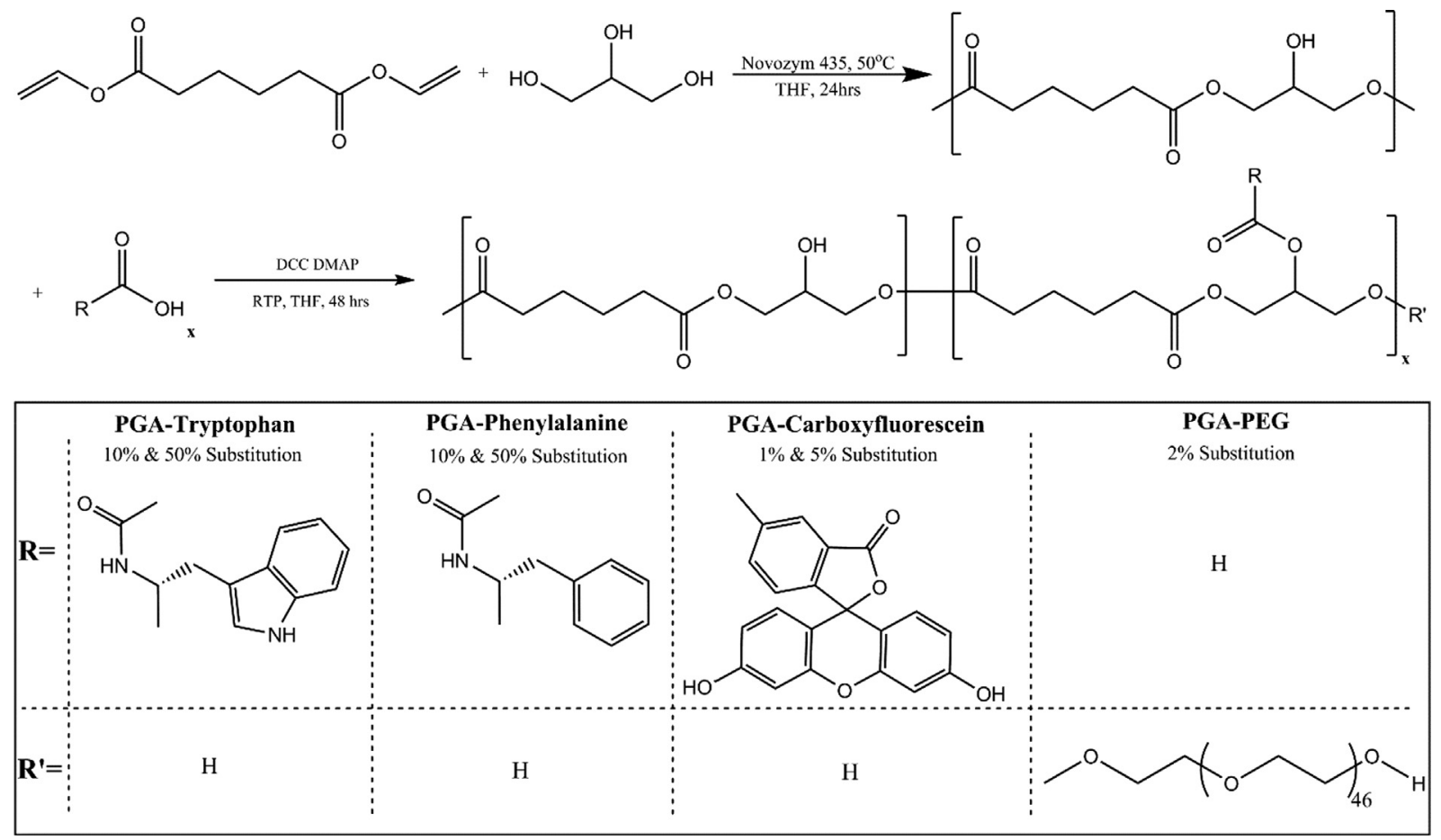

Fig. 1. Synthesis and Modification of PGA. The reaction scheme for the synthesis of PGA and subsequent modification by Steglich Esterification is shown here. Adapted from Taresco et al. [1,4].

measurement or after $6 \mathrm{~h}$.

The degradation of PGA, PGA-CF and PGA-CF5 was monitored in the presence of elastase and esterase. Analysis of degradation by elastase was carried out in both Tris buffer $(0.1 \mathrm{mM}, \mathrm{pH} 8.0)$ and Hepes buffer ( $0.5 \mathrm{M}, \mathrm{pH} 6.5)$. The enzyme solution was at a concentration of 1.74 units $/ \mathrm{ml}$, assessed using the method provided by Sigma-Aldrich, [Appendix B.1 Elastase] whereby one unit of elastase is defined as the amount that will hydrolyse $1.0 \mu$ mole of N-succinyl-L-Ala-Ala-Ala-pnitroanilide per minute at $\mathrm{pH} 8.0$ at $25^{\circ} \mathrm{C}$ in Tris buffer $(0.1 \mathrm{mM})$ [24]. For the experiments with esterase 75.3 units $/ \mathrm{ml}$ of enzyme in borate buffer (10 mM, pH 8.0) and 225.9 units/ml in phosphate buffered saline (PBS, pH 7.4) were used as the enzyme solutions. Activity was assessed using a method available from Sigma-Aldrich, [Appendix B.2 Esterase] with one unit defined as the amount that will hydrolyse $1.0 \mu$ mole of ethyl butyrate to butyric acid and ethanol per minute at $\mathrm{pH} 8.0$ at $25^{\circ} \mathrm{C}$ in borate buffer (10 $\mathrm{mM})$ [25].

The degradation of PGA, PGA-PEG, PGA-Phe10 \& 50 and PGATrp10 \& 50 in the presence of lipase, pancreatin, pepsin and trypsin was studied. Lipase was prepared in PBS ( $\mathrm{pH} \mathrm{7.4)} \mathrm{to} \mathrm{a} \mathrm{concentration} \mathrm{of}$ $10 \mathrm{mg} / \mathrm{ml}$ (215.4 units/ml). The novel method used for determining lipase activity can be found in Appendix B.3 Lipase; one unit was defined as the amount required to cleave 1.0 nmole of 4-methylumbellifyl butyrate (4-MUB) per minute in Tris buffer $(\mathrm{pH} 7.5,0.2 \mathrm{M})$ at room temperature and with a total reaction volume of $3 \mathrm{ml}$. The amount of $4-$ MUB cleaved was calculated using a calibration curve of the fluorescence intensity of the product, 4-methylumbelliferone [Appendix B.3 Lipase, Fig. B.4]. Pancreatin was prepared in Simulated Intestinal Fluid (pH 7.5) according to United States Pharmacopeia (USP) specifications. Pepsin was prepared in Simulated Gastric Fluid ( $\mathrm{pH} 1.2$ ) according to USP specifications. For the experiments with trypsin, 15,582 units $/ \mathrm{ml}$ of enzyme in sodium phosphate buffer ( $1 \mathrm{mM}, \mathrm{pH} 7.6)$ was used as the enzyme solution. Trypsin activity was determined using a method available from Sigma-Aldrich, [Appendix B.4 Trypsin] and one unit was defined as the amount required to produce a change in absorbance at $253 \mathrm{~nm}$ of 0.001 per minute with Na-Benzoyl-L-arginine ethyl ester as the substrate with sodium phosphate monobasic buffer (67 mM, pH 7.6) at $25^{\circ} \mathrm{C}$ in a reaction volume of $3.20 \mathrm{ml}$ [26].

\subsection{Release of carboxyfluorescein by dialysis}

Regenerated Cellulose Dialysis Tubing with a $3.5 \mathrm{kDa}$ MWCO (Type T1, Fisherbrand, Loughborough, UK) was washed in sterile water and stored in $0.1 \%$ sodium benzoate at $4{ }^{\circ} \mathrm{C}$ until use. The preparation and filling of the dialysis membranes took place in a Class II cabinet to minimise microbial contamination. Nanoparticles and buffer solutions were passed through a $0.22 \mu \mathrm{m}$ filter before use.

PGA-CF5 nanoparticles $(2 \mathrm{ml}, 1 \mathrm{mg} / \mathrm{ml})$ were placed in dialysis membranes along with enzyme solution and/or buffer up to a final volume of $5 \mathrm{ml}$. This was placed in buffer $(195 \mathrm{ml})$ and incubated at $37^{\circ} \mathrm{C}$ in a shaking water bath. Samples were periodically removed and replaced with fresh buffer. Further aliquots of enzyme were added at 3 , $6,24,48$ and $72 \mathrm{~h}$ to maintain enzyme activity. Blank experiments were carried out with each buffer with no enzyme present to differentiate between hydrolytic and enzymatic degradation. Fluorescence Intensity was measured in triplicate at an excitation wavelength of $492 \mathrm{~nm}$ and an emission wavelength of $517 \mathrm{~nm}$ using a Cary Eclipse Fluorescence Spectrophotometer (Agilent Technologies, Santa Clara, CA). Calibration curves of carboxyfluorescein in each buffer were produced and used to calculate the concentration in each sample. This concentration was used to calculate the cumulative percentage molar release of carboxyfluorescein over time.

The effect of three enzymes, lipase, esterase and elastase, was studied. The amount of enzyme used here, and for each of the remaining experiments, was equivalent to that which was used in the DLS experiments, scaled up relative to the amount of polymer used. The lipase experiments were carried out in phosphate buffered saline (PBS) at $\mathrm{pH}$ 7.4 with $4 \mathrm{mg}$ lipase used for each enzyme addition. Borate buffer ( $10 \mathrm{mM}, \mathrm{pH} 8.0$ ) was used as the buffer with esterase, with 33 units of esterase used for each enzyme addition. For the elastase experiments 0.82 units were used for each enzyme addition, and Hepes buffer $(0.1 \mathrm{M})$ was used at $\mathrm{pH} 6.5$.

\subsection{Characterisation of degraded polymer}

The degradation of PGA-CF5 in the presence of lipase, esterase and 
Effect of Polymer Modifications

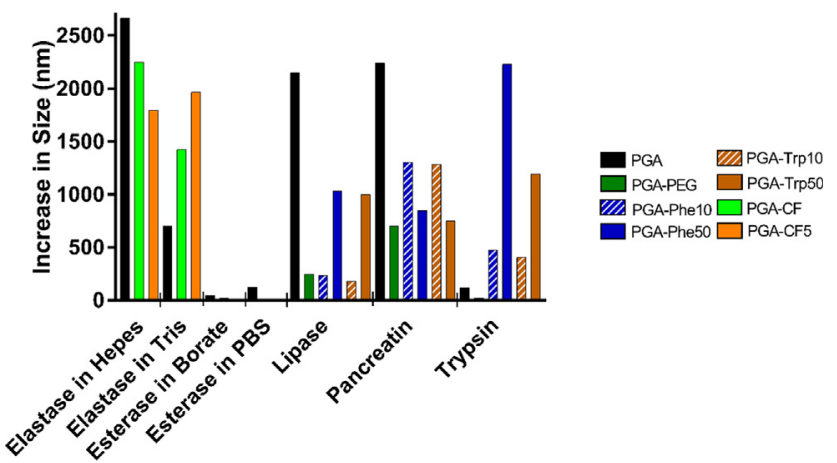

Fig. 2. Effect of Backbone Modifications on PGA Degradation. The colour of each bar here reflects the polymer under investigation. The results for pepsin have been omitted as it was not possible to differentiate the effect of the enzyme from that of the buffer.

elastase was characterised by GPC, FTIR and ${ }^{1} \mathrm{H}$ NMR. The same incubation conditions and pattern of enzyme addition as in the release experiments were used. The ratio of polymer to enzyme was maintained, however, the amount of polymer used was increased to facilitate analysis. Three incubation times, ranging from 24 to $96 \mathrm{~h}$, were used for GPC analysis and for the sample incubated with lipase analysed by NMR and FTIR. The esterase and elastase samples for NMR and FTIR analysis were incubated for $96 \mathrm{~h}$. After incubation samples were freeze-dried (Sentry 2.0, Virtis SP Scientific, Gardiner, NY) to remove the buffer.

Gel Permeation Chromatography (GPC, PL50, Polymer Laboratories, Salop, UK) was carried out using dimethylformamide $(D M F)+0.1 \% \mathrm{LiBr}$ as the mobile phase at a flow rate of $1 \mathrm{ml} / \mathrm{min}$. Two mixed bed D columns were employed, kept at a constant temperature of $50{ }^{\circ} \mathrm{C}$. Poly(methyl methacrylate) standards $\left(\mathrm{M}_{\mathrm{n}}\right.$ range $1,810,000-505 \mathrm{~g} \mathrm{~mol}^{-1}$ ) were used to calibrate the size-exclusion chromatography system. The enzyme was precipitated with acetone ( $3 \mathrm{ml}$ per sample) prior to analysis. In addition to the enzyme samples, controls were carried out using untreated PGA-CF5 and polymer which had been incubated at $37{ }^{\circ} \mathrm{C}$ without enzyme present to allow accurate interpretation of the effect of the enzymes.

FT-IR spectra were recorded with an Attenuated Total Reflection Cary 630 FTIR spectrophotometer (Agilent Technologies, Santa Clara, CA). 128 interferograms were recorded for each spectrum in the range $4000-650 \mathrm{~cm}^{-1}$.

${ }^{1} \mathrm{H}$ NMR spectra were recorded using acetone- $d_{6}$ and deuterium oxide on a Bruker $400 \mathrm{MHz}$ spectrophotometer (Billerica, MA). Chemical shifts were reported as parts per million $(\delta)$ downfield from an internal standard, tetramethylsilane. Acetone ( $1 \mathrm{ml}$ per sample, unless stated) was used to precipitate the enzyme before analysis.

\subsection{Statistical analysis}

Two-way ANOVA was performed on the results for the release of carboxyfluorescein in order to determine statistical significance. The percentage carboxyfluorescein release in the presence of each enzyme was compared with the relevant buffer without enzyme present. Following this f-tests were used to determine if the variance of the groups was significantly different. This information was used to select the appropriate two tailed unpaired $t$-test for each enzyme and buffer pair. A $t$-test was carried out at each time point to ascertain when there was a significant difference in release with and without enzyme present, with significance set at a p-value of 0.05 .

\section{Results}

\subsection{Change in particle size by Dynamic Light Scattering}

DLS was used as a rapid screening technique, monitoring the change in nanoparticle size and polydispersity following the addition of a small aliquot of enzyme. The purpose of these experiments was to gain an insight into how the polymeric nanoparticles may behave in vivo and to select appropriate conditions for future experiments. This experiment was intended to provide a binary prediction of whether or not a particular enzyme would degrade a particular polymer, rather than a quantitative measure of that degradation. It has been suggested that the increase in particle size represents swelling, followed by the collapse of the particle, which can be taken as an indication of degradation [27].

\subsubsection{Comparison of different enzymes}

The effect of each of the different enzymes on PGA nanoparticles was studied to facilitate comparison. Additionally, two buffers were used with both esterase and elastase in order to explore the impact of $\mathrm{pH}$. Together with buffers reflecting the optimum $\mathrm{pH}$ for activity, esterase was studied at $\mathrm{pH} 7.4$ to reflect the environment of the blood and elastase was studied at $\mathrm{pH}$ 6.5. In the 1920s Warburg et al. [28,29] discovered that the tumour microenvironment tends to have a slightly acidic $\mathrm{pH}$, consequently, understanding the effect of lowering the $\mathrm{pH}$ may be beneficial for future applications of this polymer in cancer drug delivery.

Simulated gastric fluid caused an increase in particle size exceeding that seen with pepsin. This is likely to be a result of the acidic $\mathrm{pH}$ of this buffer, 1.2, at which the nanoparticles do not appear to be stable. Consequently, the remainder of the results presented here exclude pepsin. The effect of the buffer was found to be negligible for all of the other conditions studied.

A dramatic change in PGA nanoparticle size was seen with lipase, pancreatin and elastase in Hepes buffer, suggesting degradation was occurring. A change in nanoparticle size was also seen with elastase in Tris buffer [Fig. 2]. The effect seen with trypsin was limited, with a small change in size in the region of $100 \mathrm{~nm}$. Additionally, the effect of esterase on particle size was limited in borate buffer $(\mathrm{pH} 8$ ) and in PBS (pH 7.4).

\subsubsection{Comparison of different polymer modifications}

Nanoparticles made using modified PGA were tested with each of the enzymes to investigate the effect of these structural changes on the extent of degradation. These modifications were the addition of PEG to the end of the polymer chain and the conjugation of carboxyfluorescein, at $2 \% \& 5 \%$, or the amino acids phenylalanine and tryptophan, at $10 \%$ and $50 \%$, to the pendant hydroxyl group of the polymer backbone. The modified polymers were compared with the unmodified PGA.

Interestingly, differences were observed between polymer modifications incubated with the same enzyme. For lipase, pancreatin and trypsin the change in size of PGA-PEG nanoparticles was an order of magnitude less than that seen for the unmodified PGA [Fig. 2]. The effect of the other modifications was less consistent. A change in size was seen for PGA and the carboxyfluorescein modified polymers upon incubation with elastase, with the extent of this change differing depending on the level of carboxyfluorescein modification. With esterase in both buffers there was no size change seen at all for the carboxyfluorescein modified polymers, and a limited effect on the size of PGA nanoparticles, meaning the differences between polymers may not be significant. For lipase and pancreatin the amino acid modifications appeared to reduce the effect of the enzymes, yet for trypsin the opposite was true. Furthermore, for all polymers with trypsin it took some time before any change in size was seen. 

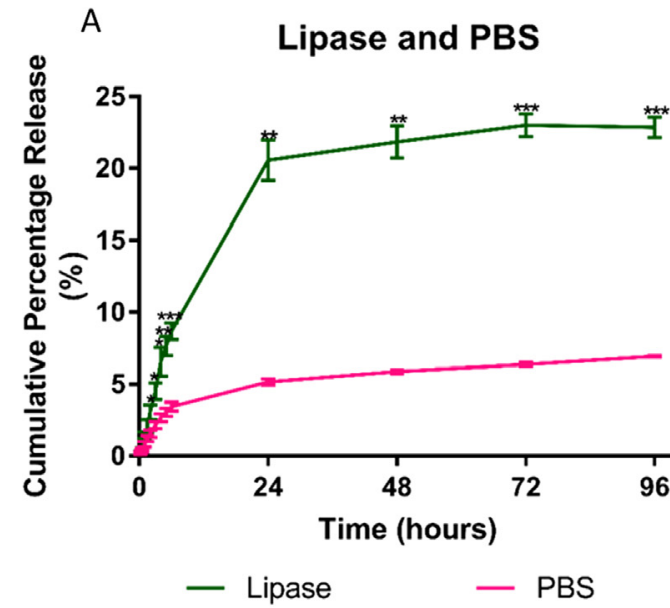

B

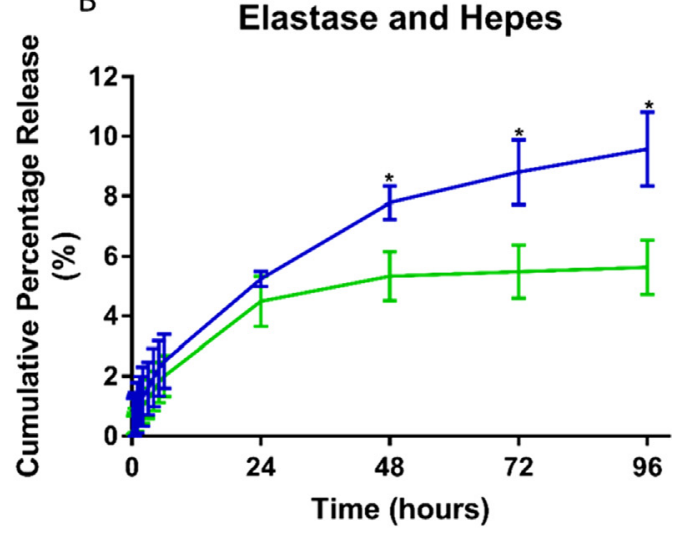

- Elastase $\quad$ Hepes

C

Esterase and Borate Buffer

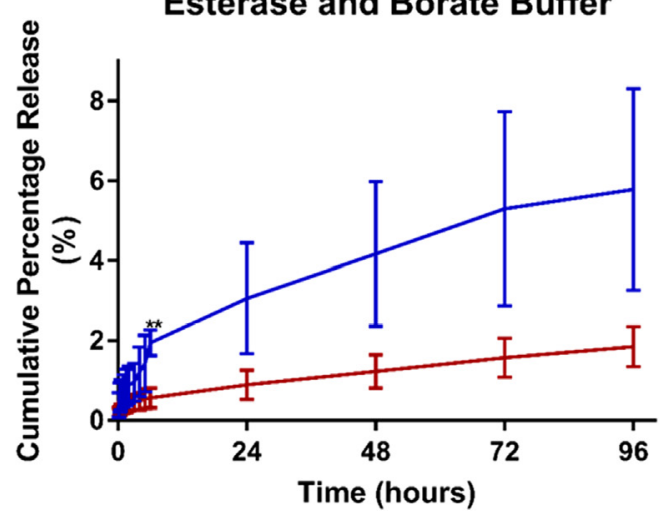

- Esterase - Borate Buffer

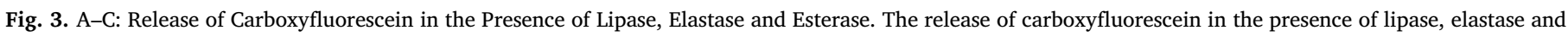

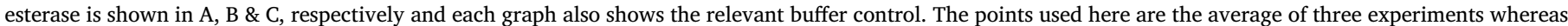

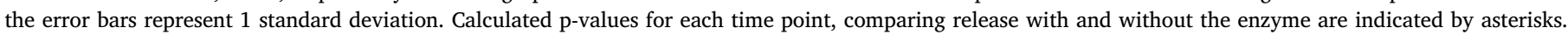

\subsection{Release of coupled carboxyfluorescein}

PGA-CF5 was used here as a model of a low loading of drug coupled to PGA, allowing the release of carboxyfluorescein from the polymer to be monitored over time. This was to provide an indication of the way a drug would be released if coupled to the polymer backbone.

Lipase was seen to significantly increase the release of carboxyfluorescein in comparison with the buffer alone [Fig. 3A]. Two-way ANOVA analysis suggested this difference was highly significant with a p-value of $<0.0001$. Furthermore, studying each time point individually suggested a significant difference between the release of carboxyfluorescein with and without lipase present from $2 \mathrm{~h}$ onwards. After $96 \mathrm{~h}$ the release of carboxyfluorescein in the presence of lipase was calculated as $23 \%$ whereas in PBS alone it was $7 \%$. Several distinct phases could be identified in the release of the carboxyfluorescein. There was an initial burst release over the first few hours; this is thought to be due to the ester bonds of carboxyfluorescein present in the surface layers of the nanoparticles being easily accessible to the enzyme and so rapidly cleaved, releasing the dye. Following this there was a more gradual release of the internal carboxyfluorescein before approaching a plateau from $24 \mathrm{~h}$ onwards. The release was not calculated to be $100 \%$, however, no carboxyfluorescein could be detected within the dialysis membrane, suggesting a spectral shift may be occurring which reduces the apparent concentration of carboxyfluorescein. The release seen here is typical for many polymeric nanoparticle formulations [30].

The experiments investigating the effect of elastase were carried out in the presence of Hepes buffer at $\mathrm{pH}$ 6.5. These conditions were chosen as $\mathrm{pH} 6.5$ saw a larger particle size increase by DLS than $\mathrm{pH}$ 8.0. Elastase caused a significant increase in carboxyfluorescein release when compared with the buffer alone from $48 \mathrm{~h}$ onwards, with p-values $<0.05$. The release was calculated as $5.6 \%$ with the buffer alone and $9.6 \%$ in the presence of elastase after $96 \mathrm{~h}$; this increase was less than that seen with lipase [Fig. 3B].

Since the DLS results for esterase at both $\mathrm{pH}$ values failed to show an effect, borate buffer ( $\mathrm{pH}$ 8.0) was preferred for these experiments as it represents the optimum conditions for esterase action. The release of carboxyfluorescein was calculated to be $5.8 \%$ in the presence of esterase after $96 \mathrm{~h}$, compared with $1.8 \%$ with the borate buffer alone. Overall, this difference was not found to be significant. Examining each time point individually, there was a significant difference in the release at $6 \mathrm{~h}$ ( $\mathrm{p}$-value $=0.005$ ), however, this difference was not maintained. Furthermore, a high level of variability between samples was observed [Fig. 3C]. Any increase in release seen with esterase is, therefore, likely to be a result of hydrolytic degradation.

\subsection{Change in polymer molecular weight following incubation with enzymes}

The release of carboxyfluorescein detailed in the previous section strongly suggests the polymer was breaking down in the presence of enzymes. In order to analyse this in a quantitative manner, GPC was used to monitor the effect of incubation with enzymes on the molecular weight of PGA-CF5. The chromatographs and distribution plots generated for each sample can be found in the Supplementary Information 

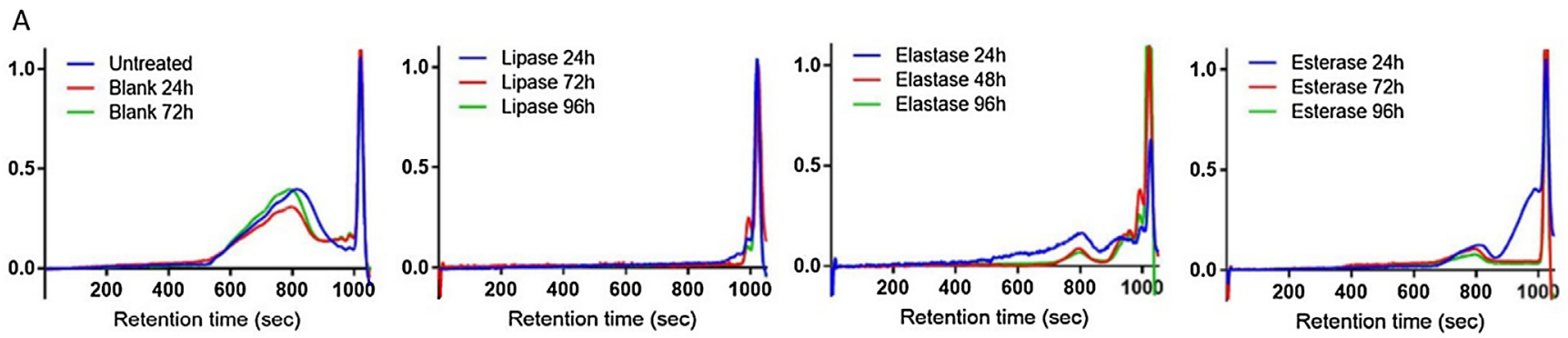

B

\begin{tabular}{|c|c|c|}
\hline Sample & Mn & $\boldsymbol{D}$ \\
\hline Untreated & 18613 & 2.80 \\
\hline Blank - 24 hrs & 18513 & 1.66 \\
\hline Blank - 72 hrs & 28421 & 2.10 \\
\hline Blank - 96 hrs & 23007 & 2.38 \\
\hline Lipase - 24 hrs & 2328 & 1.04 \\
\hline Lipase - 72 hrs & 1173 & 1.01 \\
\hline Lipase - 96 hrs & 1257 & 1.01 \\
\hline \multirow{2}{*}{ Elastase -24 hrs } & 19143 & 1.11 \\
\hline & 3438 & 1.10 \\
\hline \multirow{2}{*}{ Elastase $-48 \mathrm{hrs}$} & 21305 & 1.10 \\
\hline & 2905 & 1.07 \\
\hline \multirow{2}{*}{ Elastase -96 hrs } & 20836 & 1.09 \\
\hline & 2678 & 1.06 \\
\hline \multirow{2}{*}{ Esterase - 24 hrs } & 21963 & 1.25 \\
\hline & 1860 & 1.13 \\
\hline Esterase -72 hrs & 16610 & 1.05 \\
\hline Esterase - 96 hrs & 23725 & 1.14 \\
\hline
\end{tabular}

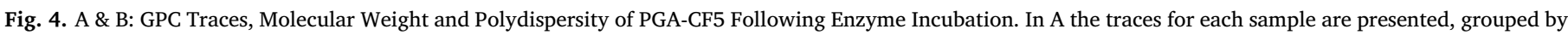

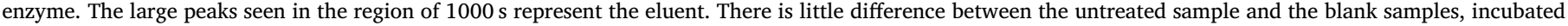

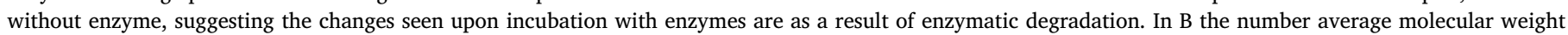
(Mn) and Polydispersity (Đ) are listed.

\section{[Appendix C].}

Where no enzyme was present there was relatively little change in the GPC traces compared with the untreated sample, suggesting PGA was stable at $37^{\circ} \mathrm{C}$ for the duration of the time period studied [Fig. 4A].

Upon incubation with lipase, a dramatic decrease in molecular weight was observed at $24 \mathrm{~h}$, with a similar result seen for the remaining time points [Fig. 4]. The peak representing the intact polymer as seen in the untreated sample was absent, suggesting no polymer remained. Only small molecular fragments were detected, however these could not be quantified as they approached the calibration limit of the instrument and the solvent peak.

At each studied time point two peaks were detected for those samples incubated with elastase; the first of these peaks represents a size consistent with untreated polymer whereas the second represents small breakdown products [Fig. 4]. Interestingly, with increasing incubation time, the size of the peak representing the intact polymer decreased relative to the peak of the small breakdown products. This suggests partial degradation occurs with elastase, with the amount of intact polymer decreasing over time as the degradation progresses.

The change seen following incubation with esterase was less dramatic than that observed with lipase and elastase, with a limited change in molecular weight [Fig. 4A]. However, the range of molecular weights appeared to narrow and the polydispersity $(\nexists)$ decreased relative to the untreated sample [Fig. 4B]. This change indicates the loss of small fractions from the end of the larger polymer chains, rather than breakages from the centre of the chain.

The GPC analysis confirms that PGA-CF5 is entirely broken down in the presence of lipase, with no intact polymer chains remaining. Degradation also occurs to a lesser extent in the presence of elastase, with both degraded and intact chains present in each sample. Finally, there is a change in the size distribution of PGA-CF5 incubated with esterase, suggesting minimal degradation is occurring.

\subsection{Changes to chemical structure of PGA following enzyme incubation}

The changes to the structure of PGA following the addition of enzymes was investigated in order to confirm breakdown was occurring and to understand the spectral changes seen with the released carboxyfluorescein.

\subsubsection{FTIR}

FTIR was used to provide a rapid indication of whether degradation had occurred. Several differences can be seen between the spectra of PGA-CF5 alone and those of the polymer incubated with lipase. The $\mathrm{OH}$ stretch between 3500 and $3000 \mathrm{~cm}^{-1}$ shifts to lower wavelengths with time, indicative of the presence of carboxylic acid groups, increased hydrogen bonding and the formation of dimers [Fig. 5A, peak I]. The peak representing the $\mathrm{C}=\mathrm{O}$ ester bond at $1750 \mathrm{~cm}^{-1}$, visible in the untreated sample, is not seen from $72 \mathrm{~h}$ of incubation with lipase onwards. Instead, there is a broad area of peaks between 1700 and $1500 \mathrm{~cm}^{-1}$, representing overlapping vibrations from a range of different $\mathrm{C}=\mathrm{O}$ carboxyl bonds [Fig. $5 \mathrm{~A}$, peak II]. Finally, there are new peaks visible in the region of the spectra below $1000 \mathrm{~cm}^{-1}$ which are not seen with the untreated PGA-CF5; these peaks represent changes to the environment of the aromatic ring structure of carboxyfluorescein [Fig. 5A, peak III]. These changes to the FTIR spectra appear likely to show the breakdown of the ester bond, and subsequently the polymer, on incubation with lipase.

PGA-CF5 incubated with elastase, the untreated polymer and the enzyme alone were analysed by FTIR and the spectra compared; two 

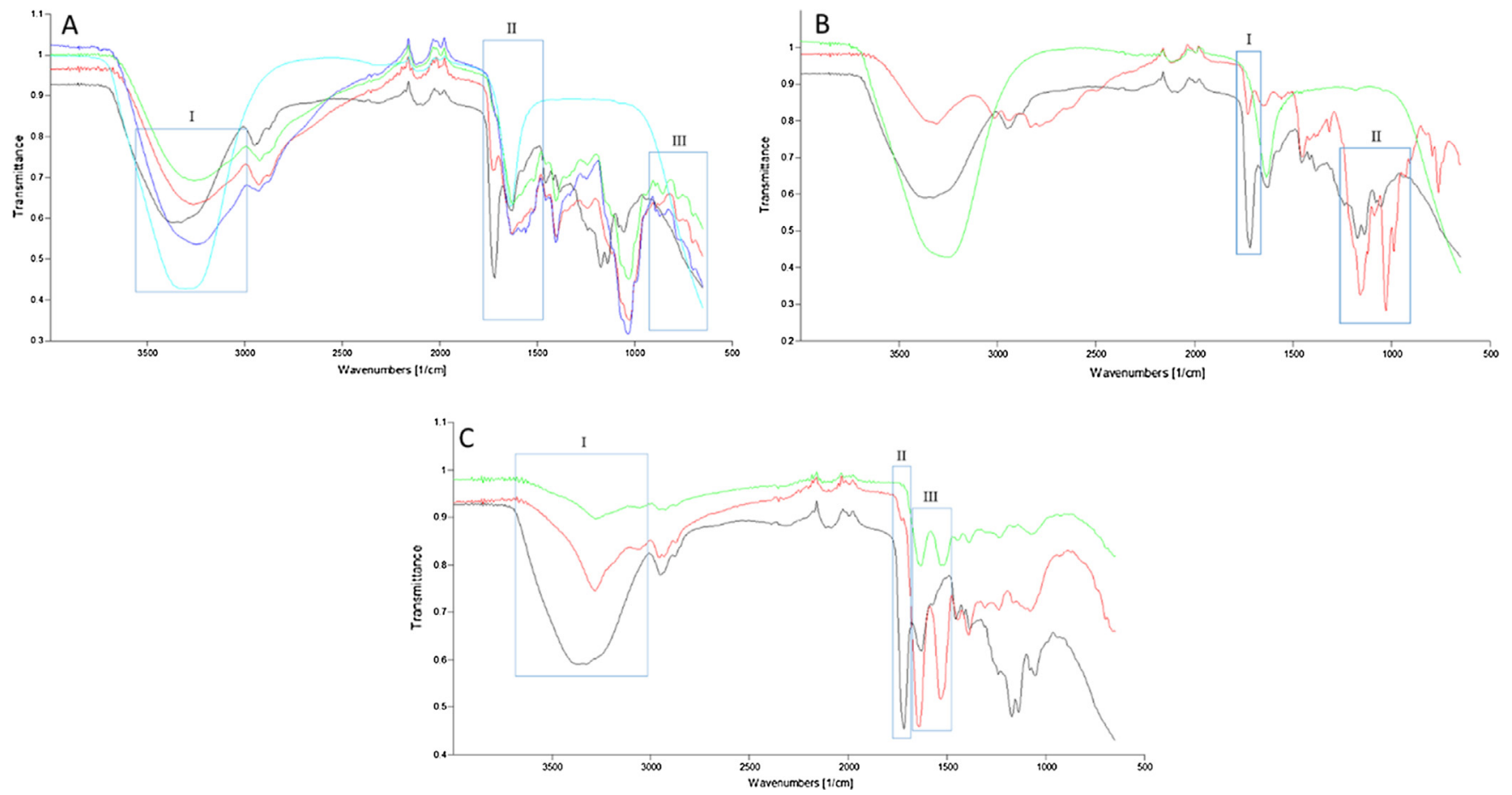

Fig. 5. A-C: FTIR Spectra of PGA-CF5 Before and After Incubation with Enzymes. Incubation with lipase is shown in A, elastase in B and esterase in C. The key differences in the spectra are highlighted with blue boxes and the peak allocation is discussed in the text. In all cases the spectrum for untreated PGA-CF5 is shown in black. For lipase (A) PGA-CF5 after $24 \mathrm{~h}$ incubation with lipase is in red; $72 \mathrm{~h}$ incubation is in green and $96 \mathrm{~h}$ incubation is in dark blue. Lipase alone is shown in sky blue. For elastase and esterase (B \& C), PGA-CF5 incubated with the respective enzyme is shown in red and the enzyme alone is shown in green. (For interpretation of the references to colour in this figure legend, the reader is referred to the web version of this article.)

main areas of difference were identified. As with the lipase samples, the peak at $1750 \mathrm{~cm}^{-1}$ [Fig. $5 \mathrm{~B}$, peak I], representing the $\mathrm{C}=\mathrm{O}$ of the ester bond, reduced in intensity between the untreated and treated samples, suggesting a proportion of these bonds were broken. Additionally, three peaks appeared at 990, $1030 \& 1160 \mathrm{~cm}^{-1}$ [Fig. 5B, peak II] in the sample incubated with enzyme, representing a $\mathrm{C}-\mathrm{O}$ alcohol bond forming in place of the ester bond.

PGA-CF5 incubated with esterase, untreated PGA-CF5 and esterase alone were analysed by FTIR and the spectra compared to ascertain the effect of the enzyme. The enzyme alone produced two clear peaks at $1530 \& 1640 \mathrm{~cm}^{-1}$ [Fig. 5C, peak III] which can also be seen for the incubated sample. The main difference between the spectra of the treated and untreated PGA-CF5 is the $\mathrm{OH}$ stretching area at $3500-3000 \mathrm{~cm}^{-1}$, the $\mathrm{OH}$ stretching area where the typical broad peak representative of alcohols, seen in the untreated sample, is replaced by a sharp acidic peak due to the formation of dimers [Fig. 5C, peak I]. Additionally, the peak at $1720 \mathrm{~cm}^{-1}$ [Fig. 5C, peak II], resulting from the $\mathrm{C}=\mathrm{O}$ ester bond, disappears following incubation with the enzyme, providing further suggestion of breakdown.

\subsection{2 ${ }^{1} \mathrm{H} \mathrm{NMR}$}

${ }^{1} \mathrm{H}$ NMR was used to provide a more detailed examination of the structural changes following incubation with the enzymes. Analysis was carried out in acetone- $d_{6}$ and deuterium oxide. Any remaining polymer would be visible in the acetone but would not be present in the deuterium oxide, whereas the degradation products would be soluble in both acetone and deuterium oxide. Consequently, this allowed the degradation products to be identified more easily in deuterium oxide in the absence of the intact polymer peaks. Allocation of the peaks corresponding to PGA has been discussed previously in detail by Taresco et al. [1].

Following incubation with lipase, it was possible to observe peaks corresponding to carboxyfluorescein (6.5-8.0 ppm), glycerol (3.5-4.0 ppm), adipic acid (1.3 ppm) and the intact polymer (1.6, 2.3,
$4.0 \mathrm{ppm}$ ) in acetone- $d_{6}$ [Fig. 6A \& B]. Furthermore, a mixture of breakdown products could be observed in the region of 4.75-5.5 ppm, with peaks corresponding to a dimer of the repetitive unit of PGA and carboxyfluorescein coupled to one PGA monomer unit. This suggests that the breakdown is not always complete.

When analysed in deuterium oxide the peaks representing adipic acid $(0.5-2.5 \mathrm{ppm})$ remain visible; there are many peaks suggesting a range of variations are present [Fig. 6A \& C]. It was possible to study the glycerol present in more detail; as well as free glycerol (3.6, 3.7, 3.9, $5.1 \mathrm{ppm}$ ) there is also a conjugate of glycerol and carboxyfluorescein (4.4 ppm). Additionally, the peak labelled $\mathrm{j}(8.0-8.3 \mathrm{ppm})$, which represents the proton adjacent to the ester bond of carboxyfluorescein, shifts with increasing incubation time as the environment changes, confirming the breakdown of this bond.

The NMR spectra of PGA-CF5 incubated with elastase, recorded in acetone- $d_{6}$ and deuterium oxide, do not differ significantly from those seen with lipase. The same breakdown products can be observed, with the polymer breaking down both partially and fully. As a result of this similarity the data is not presented here.

As with the lipase and elastase samples, esterase was precipitated from the incubated sample before ${ }^{1} \mathrm{H}$ NMR analysis in acetone- $d_{6}$ and deuterium oxide. It proved difficult to precipitate the enzyme from the sample following freeze drying; a large amount of acetone was required and the enzyme was seen to be yellow in colour, suggesting carboxyfluorescein remained within the precipitate. The spectrum obtained when analysing the incubated sample in acetone- $d_{6}$ appeared to be broadly similar to the spectra obtained for the lipase and elastase samples, albeit with less clarity [Fig. 6D]. The peaks for the polymer, adipic acid, glycerol and carboxyfluorescein remained visible. Again, breakdown products could be seen in the region of 5.0-5.5 ppm, however, there was no peak visible at $4.75 \mathrm{ppm}$ as was seen for lipase [Fig. 6A, peak q]. This peak represents the proton adjacent to the secondary alcohol of glycerol found in the dimer [Fig. 6A]. The presence of a peak at $5.3 \mathrm{ppm}$ suggests the dimer is produced, however, it is likely 
A

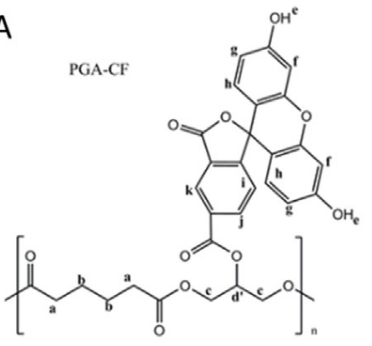

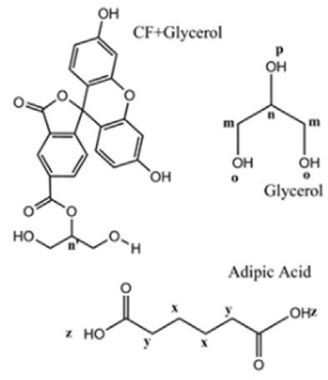

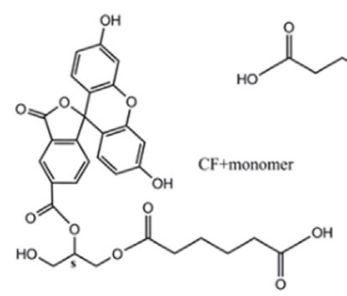

C

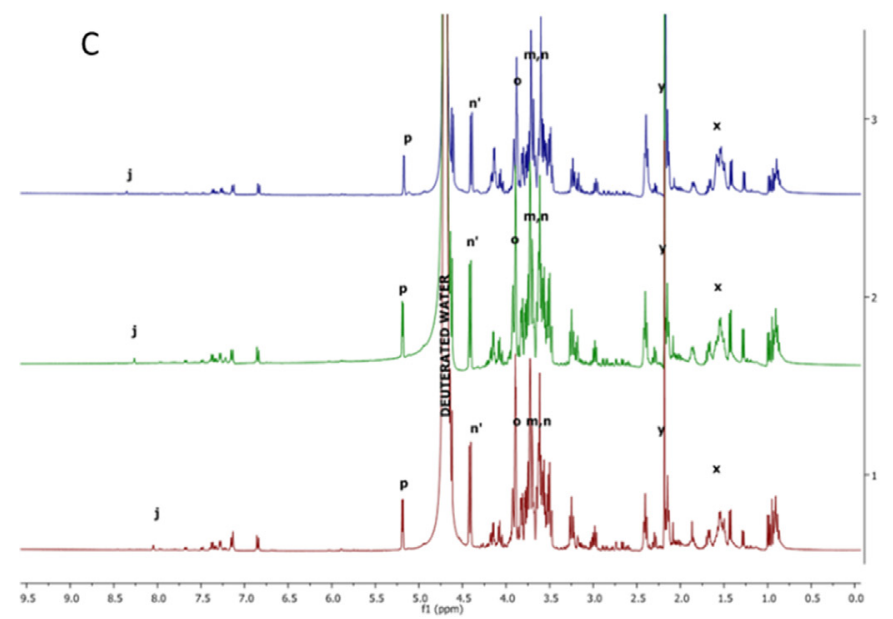

B
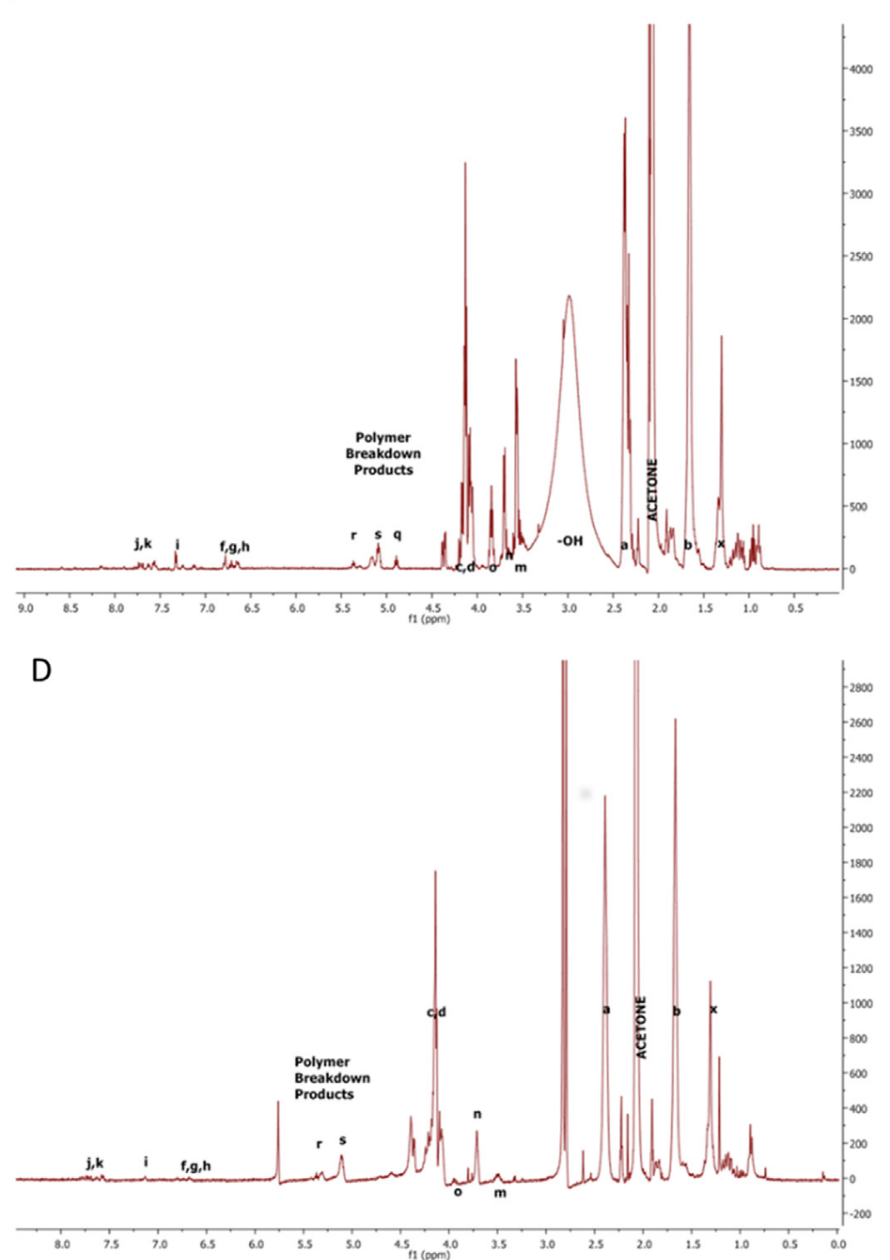

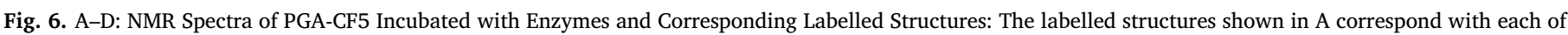

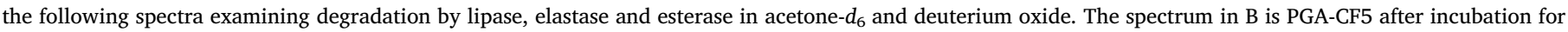

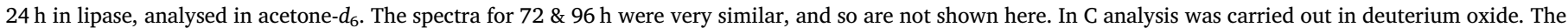

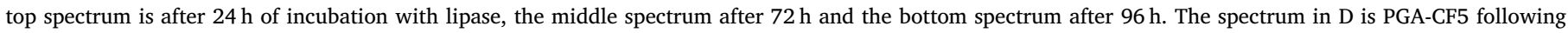

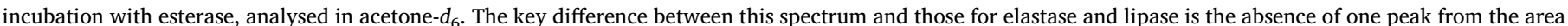
labelled 'Polymer Breakdown Products'.

to be in a small amount. Otherwise, the same breakdown products were as seen with lipase and elastase.

When analysed in deuterium oxide, the spectrum for PGA-CF5 incubated with esterase lacked definition. Areas of the spectrum relating to carboxyfluorescein, glycerol and adipic acid could be identified, however, it was not possible to allocate specific peaks. Consequently, this spectrum has not been displayed here. This is likely to be a result of the difficulty precipitating the enzyme, however, this precipitation was essential to gain any level of spectral clarity.

\section{Discussion}

DLS showed that the size of PGA nanoparticles increases after the addition of a range of enzymes, with the extent of this change differing depending on the enzyme and polymer modifications. Lipase and elastase were found to significantly increase the release of carboxyfluorescein, compared with buffer alone. The calculated release remained below $100 \%$, however, the presence of carboxyfluoresceinmonomer and carboxyfluorescein-glycerol conjugates, identified by NMR, in the polymer degradation products may provide an explanation for the observed spectral shift, and consequent underestimation of release. NMR, FTIR and GPC were also used to confirm the breakdown of the polymer in the presence of lipase, elastase and esterase; complete breakdown was seen with lipase whereas partial breakdown could be seen with the other two enzymes.

DLS was used here as a rapid screening method. The limitation of using DLS to explore enzyme degradation in more detail is that it can be difficult to understand exactly what is changing and why. Certainly, the fact that after a point it becomes impossible to gain meaningful results would support this hypothesis. Furthermore, in this study it was noted that the attenuator number, automatically selected by the Zetasizer ZS to provide the best measurements, increased over time. For example, the addition of elastase in Tris buffer to PGA nanoparticles caused the attenuator number to increase from 5 to 8 , suggesting the concentration of nanoparticles in the sample was decreasing. It must also be noted that Malvern Panalytical suggest a maximum particle size of $10 \mu \mathrm{m}$, sample dependant, for the Zetasizer ZS [31] and the sizes seen here are approaching that point. Consequently, small nanometre size differences in the micrometre size range may be artefacts of the technique.

The results seen here strongly suggest PGA nanoparticles are susceptible to degradation by a number of enzymes and that modifications of the polymer backbone can influence this degradation. Further investigations were, however, required to provide a better understanding of this. As the breakdown of the polymer and the release of any drug 
was considered to be more relevant from a drug delivery perspective than changes in particle morphology, analytical techniques were preferred to imaging techniques.

Generally, aliphatic polyesters with a short chain between ester groups, such as PGA, are found to undergo hydrolysis in a biologically relevant time frame [9]. The use of lipase in the synthesis of the polymer shows it is a viable substrate and so suggests PGA will be degradable by this enzyme. These features are also found in poly(caprolactone) (PCL) which can be synthesised by enzymatic ring opening polymerisation using lipase. This polymer features 5 carbons between the ester groups, however, PCL is not enzymatically degraded in vivo [32]. This may be as a result of the thermal properties; PCL is solid at both room temperature and $37^{\circ} \mathrm{C}$ due to its crystalline nature [32], and consequently access of the enzyme catalytic site to the ester group may be restricted. Conversely, PGA is a viscous liquid at $37^{\circ} \mathrm{C}$ [1], and this more fluid nature can be expected to allow easier access of the enzyme, suggesting why enzymatic degradation may be observed with PGA and not with PCL. These structural features and physical properties, combined with the use of enzymatic synthesis, indicate PGA may be similarly susceptible to degradation by other hydrolases to a greater extent than traditional polyesters.

The DLS results gathered here suggest modifying the polymer backbone affects the susceptibility of PGA to enzymatic degradation. In the presence of lipase, pancreatin and trypsin PGA-PEG nanoparticles demonstrated a smaller change in size compared with unmodified PGA. This suggests PEG provides a protective role by forming a corona on the surface of the particles, sterically hindering enzyme access [33]. PGAPEG could, therefore, be adopted should a slower breakdown and release profile be desired. With lipase and pancreatin the amino acid modifications appeared to reduce the effect of the enzymes. These modifications would be expected to increase the stability of the particles as a result of $\pi-\pi$ stacking of the aromatic rings [8]. This was not seen with trypsin and may be because trypsin is a protease with high specificity for arginine and lysine residues [34], rather than the ester bonds found in PGA.

The active site of porcine pancreatic lipase (PPL) comprises a catalytic triad, with lid domain loops providing steric hindrance. However, in aqueous environments hydrogen bonds between the lid and co-lipase tend to stabilise it in an open confirmation, allowing substrate access [35], and in this case the breakdown of PGA. Furthermore, the natural substrates of PPL are glycerol esters, which would explain why it works effectively on PGA resulting in the structural changes observed by NMR and FTIR and the absence of intact polymer by GPC. Pancreatin is a mixed enzyme preparation containing lipase, trypsin, amylase, ribonuclease and protease. Consequently, the effect of pancreatin would be expected to be a summation of the contribution of each of these enzymes, meaning the degradation of PGA by pancreatin would be expected to equal or exceed that seen with lipase alone.

Porcine pancreatic elastase (PPE) is a serine protease with broad specificity [36] and crystalline PPE has been reported to have a relatively open active site [37]. While the specificity of elastase is generally discussed in terms of peptides, this open site and the noted broad specificity may suggest a reason why release was seen with this particular enzyme preparation. While breakdown is evident by NMR, FTIR and GPC, the results were less clear than those seen with lipase. This may be as a result of the reduced specificity of the enzyme, when compared with lipase, resulting in partial degradation. This finding is in agreement with the lower release of carboxyfluorescein and the presence of intact polymer following GC analysis of PGA-CF5 incubated with elastase.

The active site of esterase has been reported to be highly constrained as a result of the surrounding amino acids. The Jones Cubic Space model has been used to predict whether or not a molecule will be a substrate for carboxyesterase [38]. Carboxyfluorescein, PGA and PGA-CF5 are much larger than the active site defined by this model, and as a result would not be expected to be substrates for esterase. This suggests a reason why carboxyfluorescein release is limited and also why a high degree of variability was observed. Whilst there is clear evidence by NMR and FTIR that PGA-CF5 undergoes degradation in the presence of esterase, it was more difficult to ascertain the structure of the breakdown products than was the case with PGA-CF5 incubated with either lipase or elastase. The low level of carboxyfluorescein release, along with the constrained nature of the active site of the enzyme, means this difficulty was not unexpected. Furthermore, the small changes in molecular weight seen when PGA-CF5 was incubated with esterase, suggesting breakdown at the end of the polymer chains, would concur with the theory regarding the constrained nature of the active site of esterase [38], as the steric hindrance would be greatly reduced at the chain ends.

In general terms the breakdown of PGA seen here is of clinical importance as it suggests breakdown would also be observed in vivo. This is crucial from a safety point of view and justifies the label 'biodegradable'. Furthermore, this breakdown, coupled with the effective release of coupled carboxyfluorescein suggests PGA would be viable as a drug delivery platform as active drug molecules could be expected to be released in a similar controlled manner. The differences seen with the various backbone modifications suggest the potential for tunable degradation which may be exploited for controlled release. Furthermore, the variable degradation and release seen with different enzymes could be used for targeting purposes; release can be expected to be higher in areas with high concentrations of lipase than where other enzymes prevail. The susceptibility of PGA to gastro-intestinal enzymes also opens the possibility for using the polymer for oral drug delivery in the future.

\section{Conclusion}

Pancreatin, lipase, elastase and trypsin were all found to cause a change in the size of PGA nanoparticles, indicative of degradation. Modifications of the polymer backbone altered the degree of size change seen; the effect was particularly pronounced for PGA-PEG, which consistently showed decreased degradation relative to unmodified PGA. Lipase, elastase and esterase were shown to increase the release of coupled carboxyfluorescein from the polymer; this increase was statistically significant with lipase and elastase. GPC analysis of the molecular weight of PGA-CF5 following incubation with lipase, elastase and esterase, provided evidence of polymer breakdown while illustrating the importance of the specificity of the enzymes on the extent of the degradation. Lipase was found to cause complete breakdown of PGA-CF5 by $24 \mathrm{~h}$, whereas elastase caused partial breakdown and the effect of esterase was limited. The structure of PGA-CF5 incubated with lipase, elastase and esterase was analysed to understand the way in which the polymer was breaking down. The breakdown of the ester bond in the PGA backbone could be seen along with the release of carboxyfluorescein, a carboxyfluorescein-monomer conjugate and a dimer of PGA.

Taken together, these data demonstrate the high enzymatic degradability of PGA based polymers into non-toxic building blocks by a range of relevant enzymes. Interestingly, a low level of PEGylation or varying the nature of the free hydroxyl group in the polymer backbone by conjugation with amino acids has been shown to affect the susceptibility of the polymer to degradation. This phenomenon may be exploited to tune the degradation of PGA for specific pharmaceutical or biomedical applications in order to achieve controlled release rates and breakdown profiles, thereby optimising dosage regimens and patient adherence.

\section{Acknowledgements}

This work was funded and supported by the Centre for Doctoral Training in Advanced Therapeutics and Nanomedicines (School of Pharmacy, University of Nottingham), Pfizer Ltd. and the Engineering 
and Physical Sciences Research Council (EPSRC), Grant Numbers: EP/ L01646X and EP/N03371X/1.

\section{Appendix A. Supplementary material}

Supplementary data to this article can be found online at https:// doi.org/10.1016/j.ejpb.2019.07.015.

\section{References}

[1] V. Taresco, R.G. Creasey, J. Kennon, G. Mantovani, C. Alexander, J.C. Burley, M.C. Garnett, Variation in structure and properties of poly(glycerol adipate) via control of chain branching during enzymatic synthesis, Polymer (Guildf) 89 (2016) 41-49, https://doi.org/10.1016/j.polymer.2016.02.036.

[2] T. Naolou, V.M. Weiss, D. Conrad, K. Busse, K. Mäder, J. Kressler, Fatty acid modified poly(glycerol adipate) -Polymeric analogues of glycerides, ACS Symp. Ser. (2013) 39-52, https://doi.org/10.1021/bk-2013-1135.ch004.

[3] C. Korupp, R. Weberskirch, J.J. Müller, A. Liese, L. Hilterhaus, Scaleup of lipasecatalyzed polyester synthesis, Org. Process Res. Dev. 14 (2010) 1118-1124, https:// doi.org/10.1021/op1000868.

[4] L.E. Iglesias, Y. Fukuyama, H. Nonami, R. Erra-Balsells, A. Baldessari, A simple enzymatic procedure for the synthesis of a hydroxylated polyester from glycerol and adipic acid, Biotechnol. Tech. 13 (1999) 923-926, https://doi.org/10.1023/ A:1008958212814.

[5] V.M. Weiss, T. Naolou, G. Hause, J. Kuntsche, J. Kressler, K. Mäder, Poly(glycerol adipate)-fatty acid esters as versatile nanocarriers: From nanocubes over ellipsoids to nanospheres, J. Control. Release. 158 (2012) 156-164, https://doi.org/10.1016/ J.JCONREL.2011.09.077.

[6] P. Kallinteri, S. Higgins, G.A. Hutcheon, C.B. St, M.C. Garnett Pourçain, Novel functionalized biodegradable polymers for nanoparticle drug delivery systems, Biomacromolecules 6 (2005) 1885-1894, https://doi.org/10.1021/bm049200j.

[7] V.M. Weiss, T. Naolou, T. Groth, J. Kressler, K. Mäder, In vitro toxicity of stearoylpoly(glycerol adipate) nanoparticles, J. Appl. Biomater. Funct. Mater. 10 (2012) 163-169, https://doi.org/10.5301/JABFM.2012.10294.

[8] V. Taresco, J. Suksiriworapong, I.D. Styliari, R.H. Argent, S.M.E. Swainson, J. Booth, E. Turpin, C.A. Laughton, J.C. Burley, C. Alexander, M.C. Garnett, New Nacyl amino acid-functionalized biodegradable polyesters for pharmaceutical and biomedical applications, RSC Adv. 6 (2016) 109401-109405, https://doi.org/10. 1039/c6ra21464a.

[9] V. Taresco, J. Suksiriworapong, R. Creasey, J.C. Burley, G. Mantovani, C. Alexander, K. Treacher, J. Booth, M.C. Garnett, Properties of acyl modified poly (glycerol-adipate) comb-like polymers and their self-assembly into nanoparticles, J. Polym. Sci. Part A Polym. Chem. 54 (2016) 3267-3278, https://doi.org/10.1002/ pola.28215.

[10] S. Puri, P. Kallinteri, S. Higgins, G.A. Hutcheon, M.C. Garnett, Drug incorporation and release of water soluble drugs from novel functionalised poly(glycerol adipate) nanoparticles, J. Control. Release 125 (2008) 59-67, https://doi.org/10.1016/j. jconrel.2007.09.009.

[11] T. Wersig, M.C. Hacker, J. Kressler, K. Mäder, Poly(glycerol adipate) - indomethacin drug conjugates - synthesis and in vitro characterization, Int. J. Pharm. 531 (2017) 225-234, https://doi.org/10.1016/J.IJPHARM.2017.08.093.

[12] J. Suksiriworapong, V. Taresco, D.P. Ivanov, I.D. Styliari, K. Sakchaisri, V.B. Junyaprasert, M.C. Garnett, Synthesis and properties of a biodegradable polymer-drug conjugate: Methotrexate-poly(glycerol adipate), Colloids Surf. B Biointerf. 167 (2018) 115-125, https://doi.org/10.1016/j.colsurfb.2018.03.048.

[13] C.J. Thompson, D. Hansford, D.L. Munday, S. Higgins, C. Rostron, G.A. Hutcheon, Synthesis and evaluation of novel polyester-ibuprofen conjugates for modified drug release, Drug Dev. Ind. Pharm. 34 (2008) 877-884, https://doi.org/10.1080/ 03639040801929075.

[14] M. Dunne, O.I. Corrigan, Z. Ramtoola, Influence of particle size and dissolution conditions on the degradation properties of polylactide-co-glycolide particles, Biomaterials 21 (2000) 1659-1668, https://doi.org/10.1016/S0142-9612(00) 00040-5.

[15] E. Marin, M.I. Briceño, C. Caballero-George, Critical evaluation of biodegradable polymers used in nanodrugs, Int. J. Nanomed. 8 (2013) 3071-3091, https://doi. org/10.2147/IJN.S47186.
[16] J. Park, M. Ye, K. Park, Biodegradable polymers for microencapsulation of drugs, Molecules 10 (2005) 146-161, https://doi.org/10.3390/10010146.

[17] T. Tarvainen, M. Malin, T. Suutari, M. Pöllänen, J. Tuominen, J. Seppälä, K. Järvinen, Pancreatin enhanced erosion of and macromolecule release from 2,2bis(2-oxazoline)-linked poly( $\varepsilon$-caprolactone), J. Control. Release 86 (2003) 213-222, https://doi.org/10.1016/S0168-3659(02)00372-3.

[18] M. Longmire, P.L. Choyke, H. Kobayashi, Clearance properties of nano-sized particles and molecules as imaging agents: considerations and caveats, Nanomedicine 3 (2008) 703-717, https://doi.org/10.2217/17435889.3.5.703.

[19] H.S. Azevedo, R.L. Reis, Understanding the enzymatic degradation of biodegradable polymers and strategies to control their degradation rate, Biodegrad. Syst. Tissue Eng. Regen. Med. CRC Press, Boca Raton, FL, 2005, pp. 177-201.

[20] Q. Chen, X. Yang, Y. Li, A comparative study on in vitro enzymatic degradation of poly(glycerol sebacate) and poly(xylitol sebacate), RSC Adv. 2 (2012) 4125-4134, https://doi.org/10.1039/c2ra20113e.

[21] I. Pomerantseva, N. Krebs, A. Hart, C.M. Neville, A.Y. Huang, C.A. Sundback, Degradation behavior of poly(glycerol sebacate), J. Biomed. Mater. Res. Part A 4 (2008) 1038-1047, https://doi.org/10.1002/jbm.a.32327.

[22] S. Liang, X. Yang, X. Fang, W.D. Cook, G.A. Thouas, Q. Chen, In Vitro enzymatic degradation of poly(glycerol sebacate) -based materials, Biomaterials 32 (2011) 8486-8496, https://doi.org/10.1016/j.biomaterials.2011.07.080.

[23] M.M. Muley, A.R. Reid, B. Botz, K. Bölcskei, Z. Helyes, J.J. McDougall, Neutrophil elastase induces inflammation and pain in mouse knee joints via activation of proteinase-activated receptor-2, Br. J. Pharmacol. 173 (2016) 766-777, https://doi. org/10.1111/bph.13237.

[24] Sigma-Aldrich, Elastase (EC 3.4.21.36) continuous spectrophotometric rate assay, n.d. http://www.sigmaaldrich.com/technical-documents/protocols/biology/ enzymatic-assay-of-elastase.html (accessed March 7, 2017).

[25] Sigma-Aldrich, Enzymatic Assay of Esterase, n.d. http://www.sigmaaldrich.com/ technical-documents/protocols/biology/enzymatic-assay-of-esterase.html (accessed March 7, 2017).

[26] Sigma-Aldrich, Procedure for Enzymatic Assay of Trypsin (EC 3.4.21.4), n.d. http:// www.sigmaaldrich.com/technical-documents/protocols/biology/enzymatic-assayof-trypsin.html (accessed March 7, 2017).

[27] C. Colombo, L. Dragoni, S. Gatti, R.M. Pesce, T.R. Rooney, E. Mavroudakis, D. Moscatelli, Tunable degradation behavior of PEGylated polyester-based nanoparticles obtained through emulsion free radical polymerization, Ind. Eng. Chem. Res. 53 (2014) 9128-9135, https://doi.org/10.1021/ie4036077.

[28] O. Warburg, The metabolism of carcinoma cells, J. Cancer Res. 9 (1925) 148-163, https://doi.org/10.1158/jcr.1925.148.

[29] O. Warburg, F. Wind, N. Negelein, The metabolism of tumors in the body, J. Gen. Physiol. 8 (1927) 519-530, https://doi.org/10.1085/jpg.8.6.519.

[30] N. Kamaly, B. Yameen, J. Wu, O.C. Farokhzad, Degradable controlled-release polymers and polymeric nanoparticles: mechanisms of controlling drug release, Chem. Rev. 116 (2016) 2602-2663, https://doi.org/10.1021/acs.chemrev. 5b00346.

[31] Malvern Panalytical, Zetasizer Nano ZS, 2018. https://www.malvernpanalytical. com/en/products/product-range/zetasizer-range/zetasizer-nano-range/zetasizernano-zs (accessed September 27, 2018).

[32] M. Labet, W. Thielemans, Synthesis of polycaprolactone: a review, Chem. Soc. Rev. 38 (2009) 3484-3504, https://doi.org/10.1039/b820162p.

[33] J.S. Suk, Q. Xu, N. Kim, J. Hanes, L.M. Ensign, PEGylation as a strategy for improving nanoparticle-based drug and gene delivery, Adv. Drug Deliv. Rev. 99 (2016) 28-51, https://doi.org/10.1016/j.addr.2015.09.012.

[34] J.V. Olsen, S.-E. Ong, M. Mann, Trypsin cleaves exclusively C-terminal to arginine and lysine residues, Mol. Cell. Proteom. 3 (2004) 608-614, https://doi.org/10. 1074/mcp.T400003-MCP200.

[35] A.A. Mendes, P.C. Oliveira, H.F. De Castro, Properties and biotechnological applications of porcine pancreatic lipase, J. Mol. Catal. B Enzym. 78 (2012) 119-134, https://doi.org/10.1016/j.molcatb.2012.03.004.

[36] M.M. Burrell, Enzymes in molecular biology, in: J.M. Walker (Ed.), Methods Mol. Biol. Humana Press, Totawa, New Jersey, 1993, pp. 283-284.

[37] W. Bode, E. Meyer, J.C. Powers, Human leukocyte and porcine pancreatic elastase: $\mathrm{X}$-ray crystal structures, mechanism, substrate specificity, and mechanism-based inhibitors, Biochemistry 28 (1989) 1951-1963, https://doi.org/10.1021/ bi00431a001.

[38] E.J. Toone, M.J. Werth, J.B. Jones, Active-site model for interpreting and predicting the specificity of pig liver esterase, J. Am. Chem. Soc. 112 (1990) 4946-4952, https://doi.org/10.1021/ja00168a047. 